\author{
Бадахова Г.Х.1,2*, Ставропольский центр по гидрометеорологии и мониторингу \\ Лашманов Ю.К. ${ }^{1}$ окружающей среды, г. Ставрополь, Россия \\ Шмигельский В.А. ${ }^{2}$ Институт математики и естественных наук Северо-Кавказского \\ федерального университета, г. Ставрополь, Россия \\ badahovag@mail.ru
}

\title{
ДИНАМИКА И СОВРЕМЕННЫЙ РЕЖИМ ГРОЗОВОЙ АКТИВНОСТИ НАД ЦЕНТРАЛЬНЫМ ПРЕДКАВКАЗЬЕМ
}

Введение: В Ц Вентральном Предкавказье, которое представляет Ставропольский край наиболее часто отмечаются такие опасные метеорологические явления как гроза, град, сильный ливень, сильный ветер, жара, засуха. Ввиду высокой повторяемости гроз, которые к тому же зачастую сопровождаются интенсивными ливнями и выпадением града, исследование как современного режима грозовой активности, так и его динамики представляет особый интерес. При решении задач мониторинга грозовой активности анализ многолетних данных визуальных наблюдений за грозами на сегодняшний день не имеет альтернативы.

Материалы и методы: Анализ современного режима грозовой активности в регионе проводился по данным ежесуточных восьмисрочных наблюдений шестнадцати метеорологических станций Ставропольского края. Анализировались как ежесуточные данные - время развития грозового процесса, фактическая продолжительность отдельной грозы, число гроз в течение суток, так и ежемесячные и ежегодные данные наблюдений - число дней с грозой, суммарная годовая и сезонная продолжительность гроз, средняя продолжительность грозы в день с грозой. Кроме того, рассчитывались и анализировались характеристики грозовой активности, осредненные за различные многолетние периоды наблюдений. Кроме того, проанализирован никогда не рассматривавшийся другими исследователями аспект посуточного распределения дней с грозой - отдельных дней с грозой и периодов с ежедневными грозами.

Результаты исследования: Анализ полувекового ряда данных метеонаблюдений показал, что в целом Центральное Предкавказье является районом довольно высокой грозовой активности. При этом различия в уровне грозовой активности над низменной, равнинной, возвышенной и предгорной частями региона достаточно велики. В предгорьях дней с грозой отмечается за теплый период года вдвое больше, чем над центральной, возвышенной частью региона, и втрое больше, чем над северной, равнинной низменной частью.

Обсуждение и заключение: Несмотря на отмечающееся некоторое снижение грозовой активности на большей части территории, Центральное Предкавказье по-прежнему остается районом повышенной грозовой активности, о чем свидетельствуют как достаточно высокая повторяемость грозоградовых процессов в целом, так и масштабность и интенсивность отдельных процессов. Снижение грозовой активности отмечается в равнинной части Центрального Предкавказья, в центральных районах существенных изменений режима гроз не зафиксировано, в то время как в предгорной зоне имеет место значительное повышение грозовой активности, выражающееся в увеличении как числа дней с грозой, так и суммарной продолжительности гроз. При этом средняя продолжительность отдельного грозового процесса, в среднем за полвека увеличившаяся на 25 минут, в последние годы на большей части территории даже уменьшилась. Имеет место тенденция уменьшения одиночных дней с грозой и увеличение повторяемости периодов с ежедневными грозами. Возросла также повторяемость ночных гроз.

грозовая активность, повторяемость, продолжительность, изменение климата, орография, конвекция, циркуляция атмосферы. 
Badakhova G.Kh. Lashmanov Yu.K. Shmigelsky V.A.
Stavropol Center for Hydrometeorology and Environmental Monitoring Wednesdays, Stavropol, Russia "North-Caucasian Federal University", Stavropol, Russia, badahovag@mail.ru

\section{Dynanics and modern regime of thunderstorm activity over Central Precaucasus territory}

Introduction:

Materials and methods:

Discussion and conclusion:

Keywords:
In the Central Ciscaucasia, which represents the Stavropol Territory, such dangerous meteorological phenomena as thunderstorms, hail, heavy rain, strong wind, heat, and drought are most often observed. Due to the high frequency of thunderstorms, which are also often accompanied by intense downpours and hail, the study of both the modern thunderstorm mode and its dynamics is of particular interest. When solving the tasks of monitoring thunderstorm activity, the analysis of multi-year data of visual observations of thunderstorms has no alternative today.

The analysis of the current mode of thunderstorm activity in the region was carried out according to daily eight-term observations of sixteen meteorological stations in the Stavropol Teritory. Analyzed as daily data - the time of development of the thunderstorm process, the actual duration of an individual thunderstorm, the number of thunderstorms during the day, and monthly and annual observational data - the number of days with thunderstorms, the total annual and seasonal duration of thunderstorms, the average duration of thunderstorms per day with thunderstorms. In addition, the characteristics of thunderstorm activity, averaged over various long-term observation periods. were calculated and analyzed. In addition, the aspect of the daily distribution of days with a thunderstorm - separate days with a thunderstorm and periods with daily thunderstorms, which was never considered by other researchers: was analyzed.

Results of the research: An analysis of a half-century series of meteorological data showed that, in general, the Central Pre-Caucasus is an area of rather high thunderstorm activity. At the same time, the differences in the level of thunderstorm activity above the lowland, flat, elevated and foothill parts of the region are quite large. In the foothills of days with a thunderstorm, for the warm period of the year; twice as many as above the central, elevated part of the region, and three times more than over the northern, lowland lowland.

Despite a slight decrease in thunderstorm activity in most parts of the territory, Central Ciscaucasia still remains an area of increased thunderstorm activity; as evidenced by both the relatively high frequency of thunderstorm processes in general and the scale and intensity of individual processes. A decrease in thunderstorm activity is noted in the flat part of the Central Ciscaucasia, in the central regions there are no significant changes in the thunderstorm regime, while in the foothill zone there is a significant increase in thunderstorm activity, manifested in an increase in the number of thunderstorms and the total duration of thunderstorms. At the same time, the average duration of a separate thunderstorm process, which has increased by 25 minutes on average over half a century, has even decreased over most of the territory in recent years. There is a tendency to decrease single days with thunderstorms and an increase in the frequency of occurrence of periods with daily thunderstorms. The frequency of night thunderstorms has also increased.

thunderstorm activity, frequency, duration, climate change, orography, convection, atmospheric circulation. 


\section{Введение}

Происходящее в настоящее время изменение климата, которое вначале позиционировалось только как глобальное потепление, привело к значительному росту повторяемости и интенсивности экстремальных погодных явлений. Последствия этих явлений варьируют от катастрофических до относительно небольшого ущерба в той или иной отрасли экономики, но всегда негативны. Это, как правило, мезомасштабные явления, поэтому их анализ и прогноз должны основываться на результатах региональных климатических исследований.

В Центральном Предкавказье, которое представляет Ставропольский край, наиболее часто отмечаются такие опасные метеорологические явления как гроза, град, сильный ливень, сильный ветер, жара, засуха. Ввиду высокой повторяемости гроз, которые к тому же зачастую сопровождаются интенсивными ливнями и выпадением града, исследование как современного режима грозовой активности, так и его динамики представляет особый интерес. При решении задач мониторинга грозовой активности анализ многолетних данных визуальных наблюдений за грозами на сегодняшний день не имеет альтернативы.

\section{Материалы и методы исследования}

Анализ современного режима грозовой активности в регионе проводился по данным ежесуточных восьмисрочных наблюдений шестнадцати метеорологических станций Ставропольского края. Анализировались как ежесуточные данные - время развития грозового процесса, фактическая продолжительность отдельной грозы, число гроз в течение суток, так и ежемесячные и ежегодные данные наблюдений - число дней с грозой, суммарная годовая и сезонная продолжительность гроз, средняя продолжительность грозы в день с грозой. Кроме того, рассчитывались и анализировались характеристики грозовой активности, осредненные за различные многолетние периоды наблюдений. Кроме того, проанализирован никогда не рассматривавшийся другими исследователями аспект посуточного распределения дней с грозой - отдельных дней с грозой и периодов с ежедневными грозами.

Построены графики полувекового хода основной характеристики грозовой активности в регионе - годового числа дней с грозой и определены тренды изменения этой характеристики в различных физико-географических зонах Центрального Предкавказья.

Территория региона характеризуется резко выраженной неоднородностью рельефа, который по абсолютным высотам можно разделить на низменный (менее 100 м), возвышенный (до 500 м) и среднегорный (более 500 м). Вследствие этого на территории имеет место большое разнообразие ландшафтов - от полупустынь до остепненных лугов среднегорий - со своими климатическими особенностями. 
Во избежание излишней громоздкости материала в статье представлены результаты анализа для трех метеостанций региона, максимально разнесенных по широте на территории края, но находящихся примерно на одном меридиане и располагающихся на наиболее характерных для территории Центрального Предкавказья высотах над уровнем моря: Дивное (455' с.ш., $43^{\circ} 21^{\prime}$ в.д.; 86 м), Благодарный $\left(45^{\circ} 06^{\prime}\right.$ с.ш., $43^{\circ} 28^{\prime}$ в.д.; 161 м), Кисловодск (435'ㄷ.ш., $42^{\circ} 46^{\prime}$ в.д.; 943 м).

\section{Результаты исследования и их обсуждение}

Анализ полувекового ряда данных метеонаблюдений показал (табл. 1), что в целом Центральное Предкавказье является районом довольно высокой грозовой активности. При этом различия в уровне грозовой активности над низменной, равнинной, возвышенной и предгорной частями региона достаточно велики. В предгорьях дней с грозой отмечается за теплый период года вдвое больше, чем над центральной, возвышенной частью региона, и втрое больше, чем над северной, равнинной низменной частью.

Рассчитанное среднее многолетнее значение годового числа дней с грозой по всем станциям региона [8] за период 1961-2000 гг. позволило определить его зависимость от высоты местности в условиях Центрального Предкавказья (рис. 1). Указанный период был выбран для того, чтобы сравнить полученные результаты с результатами, полученными по расчетам за этот же период для другого района Северного Кавказа.

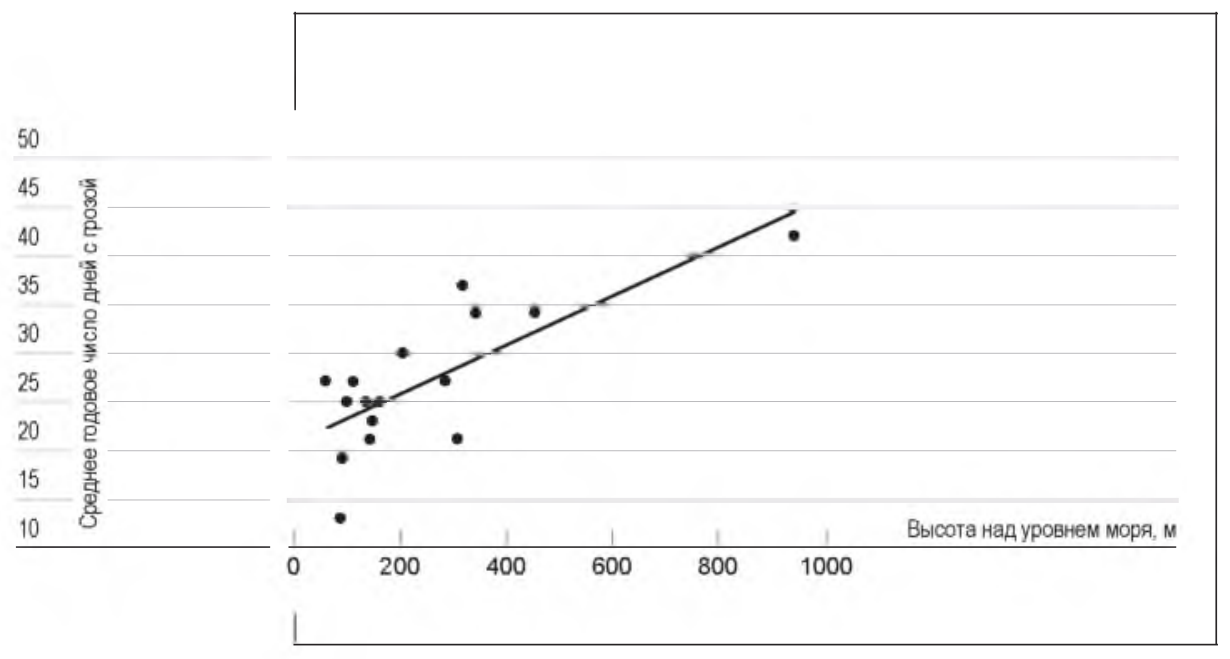

Рис. 1. Зависимость среднего годового числа дней с грозой от высоты местности для Центрального Предкавказья.

Fig. 1. Correlation between average annual amount of thunderstorm days and terrain elevation. 
Получено уравнение

$y=0.0251 x+20.788$,

в целом хорошо согласующееся с ранее полученным для этого же периода в [1] для предгорной зоны Северного Кавказа.

Таблица 1. ПОМЕСЯЧНОЕ РАСПРЕДЕЛЕНИЕ ЧИСЛА ДНЕЙ С ГРОЗОЙ Table. Monthly distribution of thunderstorm days

\begin{tabular}{l|llllllll|ll}
\hline Станция & IV & V & VI & VII & VIII & IX & X & Tก \\
\hline Дивное & 1 & 3 & 4 & 4 & 3 & 2 & 0 & 17 \\
\cline { 1 - 9 } Благодарный & 1 & 5 & 7 & 5 & 5 & 2 & $*$ & 25 \\
\cline { 2 - 9 } Кисловодск & 2.5 & 9 & 13 & 10 & 10 & 5 & 0.5 & 50 \\
\hline
\end{tabular}

Абсолютное большинство гроз отмечается в теплый период года, точнее - с апреля по сентябрь. В октябре грозы бывают редко, да и то лишь в возвышенной части региона. На холодный период приходится менее $0.5 \%$ годового числа дней с грозой. Суммарная продолжительность гроз также ожидаемо возрастает по мере увеличения абсолютной высоты местности (табл. 2), от 25-30 часов за теплый сезон по разным метеостанциям северной части края до 100 часов в верхней части Ставропольской возвышенности и в предторьях Кавказа.

Таблица 2.

ПОМЕСЯЧНОЕ РАСПРЕДЕЛЕНИЕ СУММАРНОЙ ПРОДОЛЖИТЕЛЬНОСТИ ГРО3 (ЧAC)

Table 2. Monthly distribution of the thunderstorm total duration (h)

\begin{tabular}{l|l|l|l|l|l|l|l|l}
\hline Станция & IV & V & VI & VII & VIII & IX & X & Tח \\
\hline Дивное & 1 & 5 & 8 & 6 & 5 & 3 & 0 & 28 \\
\hline Благодарный & 1 & 7 & 10 & 8 & 8 & 3 & $*$ & 37 \\
\hline Кисловодск & 2.5 & 19 & 30 & 21 & 19 & 8 & 0.5 & 100 \\
\hline
\end{tabular}

Средняя продолжительность одной грозы в целом по региону варьирует от 1.5 до 2 часов. Самые долгие грозы бушуют в Ставрополе и Кисловодске, как правило, в июне. Нередко складываются условия благоприятные для регенерации грозовых процессов, и тогда в течение суток отмечается несколько периодов грозовой активности. Самые короткие грозы бывают в апреле [ 8]. 
В Предкавказье отмечаются как одиночные дни с грозой, так и достаточно длительные периоды с ежедневными грозами (табл. 3). Однако если в равнинной зоне на одиночные дни приходится более $60 \%$ всех гроз, то в возвышенной части - менее половины, а в предгорной зоне - чуть более четверти.

Таблица 3. ДОЛЯ ДНЕЙ С ГРОЗОЙ (\%), ВХОДЯЩИХ В N-ДНЕВНЫЕ ПЕРИОДЫ (2001-2018 гг.)

Table 3. Proportion of thunderstorm days within $\mathrm{n}$-day periods

\begin{tabular}{l|l|l|l|l|l|lc}
\hline станция & \multicolumn{7}{|l}{ Продолжительность периода, дней } \\
\cline { 2 - 9 } & $\mathbf{1}$ & $\mathbf{2}$ & $\mathbf{3}$ & $\mathbf{4}$ & $\mathbf{5}$ & $\mathbf{6}$ & $\mathbf{7}$ \\
\hline Дивное & 60.8 & 24.6 & 11.5 & 3.1 & - & - & - \\
\hline Благодарный & 43.5 & 27.1 & 18.6 & 6.8 & - & - & 4.0 \\
\hline Кисловодск & 26.9 & 27.4 & 18.3 & 8.1 & 12.7 & 3.0 & 3.6 \\
\hline
\end{tabular}

Анализ динамики грозовой активности региона за последние полвека (в сравнении с многолетними данными до 1966 г. [11]) показал, что на фоне наличия значительной межгодовой изменчивости грозовой активности можно все же выделить некоторые общие тенденции.

На севере региона повторяемость гроз за последние 50 лет снизилась, в центральных районах практически не изменилась, а на юге, в предгорьях, заметно увеличилась (табл. 4, рис. 2). За первые 18 лет нового века в Дивном отмечено 379 , в Благодарном - 533, в Кисловодске - 1014 дней с грозой.

Таблица 4.

ДИНАМИКА ГОДОВОГО ЧИСЛА ДНЕЙ С ГРОЗОЙ ПО 10-ЛЕТИЯМ Table 4. Dynamics of year quantity of thunderstorm days within ten-year periods

\begin{tabular}{|c|c|c|c|c|c|c|c|c|c|}
\hline \multirow[t]{2}{*}{ Период } & \multicolumn{3}{|c|}{ Дивное } & \multicolumn{3}{|c|}{ Благодарный } & \multicolumn{3}{|c|}{ Кисловодск } \\
\hline & $\mathrm{cp}$. & макс & мин & $c p$. & макс & мин & $c p$. & макс & мин \\
\hline До 1966 & 20 & 30 & & 25 & 36 & & 34 & 49 & \\
\hline $1966-1975$ & 22 & 32 & 15 & 24 & 34 & 17 & 38 & 52 & 28 \\
\hline 1976-1985 & 19 & 27 & 11 & 24 & 33 & 18 & 43 & 57 & 33 \\
\hline 1986-1995 & 10 & 18 & 3 & 23 & 31 & 11 & 43 & 56 & 26 \\
\hline $1996-2005$ & 16 & 29 & 7 & 25 & 33 & 19 & 45 & 56 & 36 \\
\hline $2006-2015$ & 17 & 32 & 10 & 25 & 29 & 17 & 50 & 66 & 31 \\
\hline
\end{tabular}




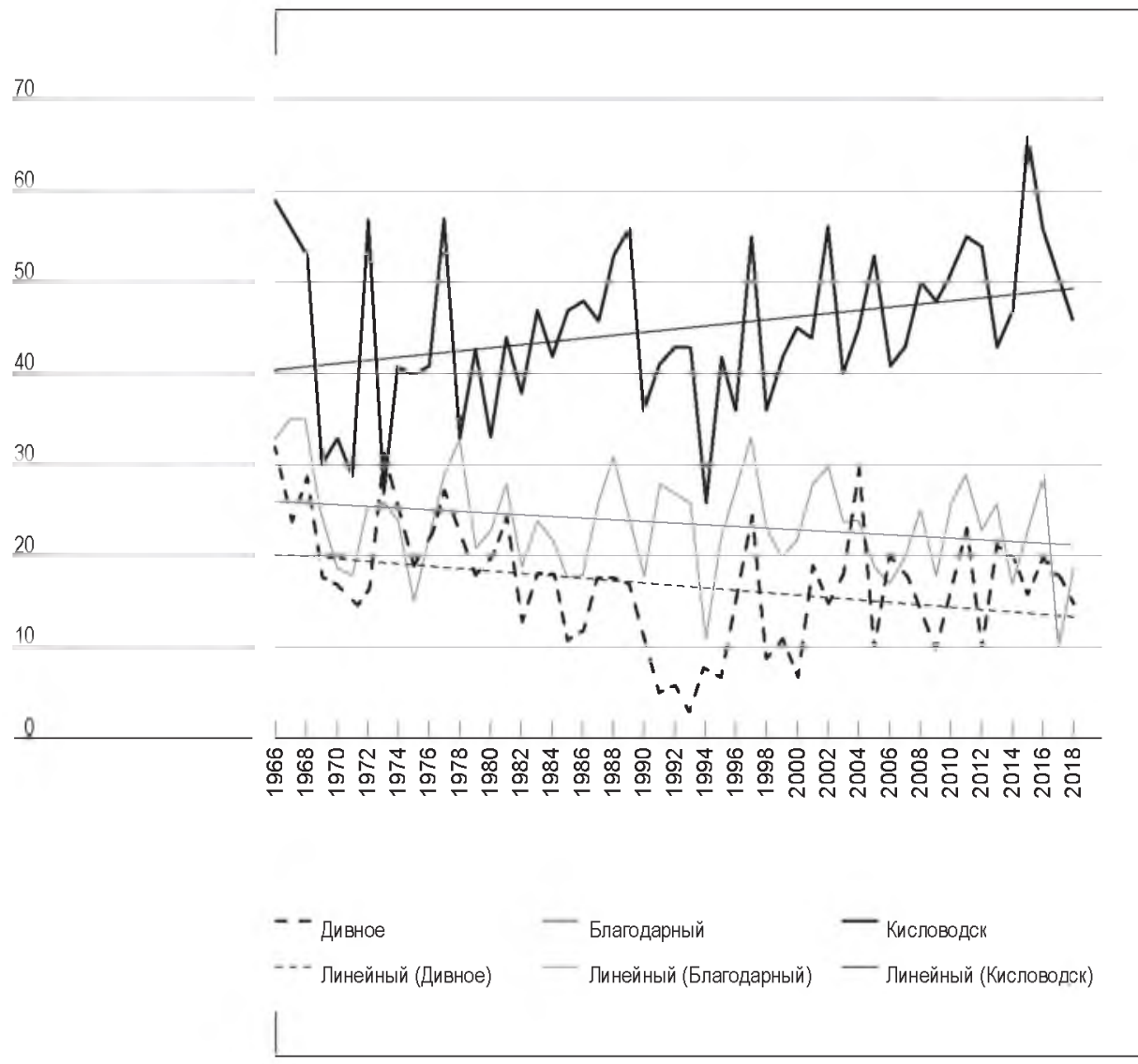

Рис. 2.

Полувековой ход годового числа дней с грозой.

Fig. 2. Annual variability of thunderstorm days quantity within a half-century period.

На основе анализа многолетнего хода годового числа дней с грозой получены уравнения трендов:

Дивного

$y=-0.1164 x+20.295$

дЛя

Благодарного

$y=-0.09 x+26.165$

для

Кисловодска

$\mathrm{y}=0.1685 \mathrm{x}+40.488$.

Что касается средней продолжительности гроз, то эта характеристика грозовой активности в Справочнике по климату СССР [11] приведена лишь для трех станций Ставропольского края. Однако на основе этих данных, а также данных по всем станщиям Центрального Предкавказья, приведенным в [8], можно сделать вывод, что суммарная продолжительность гроз также сократилась в северной, равнинной части региона, несколько увеличилась в центральной, возвышенной части и вдвое возросла в предгорной 
зоне. Так, в Кисловодске в первой половине XX века она составляла 51 час, во второй половине - 91 час, в 2001-2018 гг. - уже 104 часа. За первые 18 лет XXI века наибольшая суммарная продолжительность гроз в течение теплого периода отмечена в 2012 году в Кисловодске (131 час), наименьшая - в 2006 году в Рощино (12 часов).

Анализ суточных данных о продолжительности гроз показал, что средняя продолжительность одной грозы на юге рассматриваемой территории увеличилась на полчаса по сравнению с периодом до 1966 года и за последние полвека составила по десятилетиям от 2,0 до 2,2 часа. При этом отмечается увеличение числа дней с грозами, охватывающими большую территорию. На фоне повышения минимальных суточных температур возросла повторяемость ночных гроз. Отмеченная в [3] тенденция увеличения повторяемости многодневных периодов с грозами в целом сохраняется. Так, в первой половине XX века в Кисловодске было отмечено 11 периодов продолжительностью более 5 дней каждый, в 1961-2001 гг. таких периодов было отмечено уже 47 [4] , а за 18 лет нового века - около 30

Начало периода грозовой активности приходится 15-25 апреля. В среднем в $10 \%$ лет отмечается гроза в марте. В связи с потеплением осени возрастает повторяемость сентябрьских и октябрьских гроз, хотя октябрьские грозы - все же явление редкое. На юге региона возросла повторяемость гроз, сопровождающихся выпадением града. На севере, напротив, возросла повторяемость «сухих» гроз.

Одной из причин отмеченных изменений режима грозовой активности является, конечно же, потепление климата. Повышение температур, в том числе и в теплый период года, более существенно в северных и северо-восточных, районах рассматриваемой территории. При этом прирост температур превышает прирост осадков, и в целом эти районы становятся более засушливыми [6]. В центральной части региона в многолетнем плане изменения вышеуказанных характеристик климата примерно сбалансированы. В предгорных и среднегорных районах повышение температуры теплого периода не столь значительно, а увеличение количества осадков и дней с осадками, в том числе и с грозами, более заметно, что в огромной степени обусловлено рельефом местности [5].

Именно характер взаимодействия фронтальной поверхности с рельефом обусловливает характер мезомасштабной циркуляции, которая может как стимулировать конвекцию, так и гасить её, трансформируя общий фоновый процесс. Для территории Центрального Предкавказья, как и для всего Северного Кавказа вообще, в целом характерно широтное (в основном с запада и северо-запада) перемещение атмосферных фронтов, обусловливающих развитие конвективной облачности и формирование ливневых осадков.

При приближении к горам атмосферный фронт получает добавочную вертикальную составляющую скорости: 


$$
w_{h}=U \frac{\partial h}{\partial x}+V \frac{\partial h}{\partial y}
$$

$\begin{array}{lll}\text { где } & h- & \text { высота горного хребта, } \\ & U_{\text {и } V-} & \text { горизонтальные составляющие скорости ветра. }\end{array}$

Она существенно зависит от формы и высоты гор. В отдельных случаях она составляет 8-13 м/с, что на порядок превышает вертикальные движения воздушных масс на поверхности фронтального раздела.

Под влиянием рельефа изменяется не только скорость, но и направление движения. Так, над Северным Кавказом северо-западное перемещение часто трансформируется в северное, поскольку юго-западный участок атмосферного фронта достигает горных препятствий раньше центральной части, а тем более северо-восточной периферии. При этом юго-западный участок фронта начнет деформироваться, в то время как его центральная и северовосточная части будут перемешаться над равниной, не претерпевая изменений [12]. Активная облако- и осадкообразующая деятельность отмечается в той части края, где наблюдается оптимальное сочетание динамических, температурных и влажностных характеристик в нижней тропосфере.

Динамические характеристики нижней тропосферы в определенной степени также зависят от рельефа, поскольку орографические условия играют исключительно важную роль в формировании струи восходящего воздуха и последующего развития процесса облакообразования. В [7] получено выражение для определения скорости движения воздуха $W$ в зависимости от температуры и давления вне струи и внутри ее (обозначены индексами $i$ и $e$ соответственно):

$$
\frac{W^{2}(Z)}{2}=g \int_{Z_{1}}^{Z} \frac{T_{i}-T_{e}}{T_{e}} d Z+\frac{p_{e}-p_{i}}{\rho_{e}}
$$

откуда следует, что скорость потока в струе зависит не только от силы плавучести, определяемой разностью температур в струе и вне ее, но и от разности давлений в окружающей среде и в облаке. При значительной величине разности давлений $p_{e}-p_{i}>0$, которая в зрелом кучево-дождевом облаке достигает $\sim 10$ гПа, воздух может подниматься в нижней части струи, даже если он холоднее окружающего, т. е. при $\Delta T=T_{e}-T_{i}>0$.

В этой же работе проведена оценка термодинамических параметров воздуха в струе $\left(T_{i}, p_{i}, \rho_{i}\right)$ на различных уровнях. Получено, что на верхнем уровне 


$$
\frac{W^{2}\left(Z_{2}\right)}{2}=g \int_{Z_{1}}^{Z_{1}} \frac{T_{i}-T_{e}}{T_{e}} d Z=0,
$$

то есть при стационарном течении процесса и отсутствии трения суммарная удельная

механическая энергия при прохождении воздуха от нижнего уровня до верхнего равна нулю. Таким образом, из последнего уравнения следует, что струя включает в себя области, где воздух как теплее $(\Delta T>0)$. так и холоднее $(\Delta T<0)$ окружающего атмосферного воздуха. Ниже уровня $Z_{1}$ (при $Z_{1} \gg 0$ ) и выше уровня $Z_{2}$ температура в облаке ниже, чем в окружающей атмосфере.

Таким образом, в нижней части струи температура поднимающегося воздуха меньше, чем в окружающей атмосфере $(\Delta T<0)$, давление также меньше $(\Delta p<0)$, а плотность воздуха - больше $(\Delta \rho>0)$. В верхней части мощной восходящей струи наблюдается аналогичная картина, а в центре струи температура воздуха больше, а плотность и давление меньше, чем в окружающей атмосфере [7]. При этом баланс разностей температур в целом в струе нулевой.

Из вышеизложенного следует, что при отрицательной плавучести в основании облака развитие восходящих потоков, т.е. конвекции, возможно за счет динамического фактора. Полученный теоретический результат объясняет формирование конвективной облачности и выпадения ливневых осадков в предгорной и среднегорной части территории при относительно невысоком температурном фоне.

Исследования Института географии РАН [9] показали, что росту повторяемости гроз способствовали изменения атмосферной циркуляции, необычайно высокая активность южных циклонов, связанная с повышенной теплоотдачей океана в атмосферу в тропических широтах. В конще XX века произошел резкий скачок продолжительности меридиональных южных процессов. При этом продолжительность меридиональной северной группы осталась по-прежнему высокой, а все остальные группы циркуляций заметно сократились. Такая перестройка атмосферной циркуляции благоприятствует беспрепятственному прохождению вторгающихся с севера воздушных масс через открытые для них равнинные северные районы Предкавказья, частичному стимулированию конвекции в центральных районах, равно прикрытых орографически как широтно, так и меридионально, и значительному усилению конвекции в предгорной зоне на фоне снижения широтного переноса.

\section{Выводы}

Несмотря на отмечающееся некоторое снижение грозовой активности на большей части территории, Центральное Предкавказье по-прежнему остается районом повышенной грозовой активности, о чем свидетель- 
ствуют как достаточно высокая повторяемость грозоградовых процессов в целом, так и масштабность и интенсивность отдельных процессов. Снижение грозовой активности отмечастся в равнинной части Центрального Предкавказья, в центральных районах существенных изменений режима гроз не зафиксировано, в то время как в предгорной зоне имеет место значительное повышение грозовой активности, выражающееся в увеличении как числа дней с грозой, так и суммарной продолжительности гроз. При этом средняя продолжительность отдельного грозового процесса, в среднем за полвека увеличившаяся на 25 минут, в последние годы на большей части территории даже уменьшилась. Имеет место тенденция уменьшения одиночных дней с грозой и увеличение повторяемости периодов с ежедневными грозами. Возросла также повторяемость ночных гроз.

Важнейшими причинами изменения режима грозовой активности являются потепление климата и, в особенности, изменения атмосферной циркуляции, тип которой обусловливает характер взаимодействия атмосферных фронтов с рельефом и возникновение мезомасштабной циркуляции. Трансформация динамической структуры фронтальных поверхностей в условиях Центрального Предкавказья происходит при их продвижении к югу и по мере перехода рельефа от равнинного к горному обусловливает определенную трансформацию полей метеоэлементов в нижней тропосфере, которая инициирует развитие конвекции или тормозит ее.

Теоретически показано, что рельефу как динамическому фактору принадлежит исключительно важная роль в процессе формирования и развития конвективных процессов в атмосфере, вплоть до возникновения конвективных движений в условиях отрищательной плавучести. Произошедшие изменения атмосферной циркуляции усилили действие динамического фактора, что привело к повышению грозовой активности в южных и юго-западных районах Центрального Предкавказья, в условиях относительно больших высот и значительной расчлененности рельефа.

\section{Библиографический список}

1. Аджиев А.Х. Климатологические и статистические характеристики гроз на Кавказе // Тр. ВГИ. 1999. Вып. 90. С. 64-70.

2. Аджиев А.Х., Аджиева А.А., Тумгоева Х.А. Влияние орографии на характеристики грозовой активности деятельности // Известия вузов. Северо-Кавказский регион. Естественные науки. 2008. № 3. С. 109-112.

3. Аджиев А.Х., Бадахова Г.Х. Динамика грозовой активности в регионе Кавказских Минеральных Вод в XX веке//Физика облаков 
и активные воздействия на гидрометеорологические процессы: Доклады Всероссийской конференции. Москва, 2008. С. 206213.

4. Бадахова Г.Х., Акопов ГА. Вековой мониторинг грозовой активности в предгорной зоне Центрального Предкавказья // Теоретические и практические аспекты научной мысли в современном мире: Сб. статей международной научно-практической конференции в 4 частях. Оренбург, 2017. С. 25-29.

5. Бадахова Г.Х., Байрамкулова Б.О., Гаджимурадова З.М., Джандубаева Т.З. Мониторинг современных климатических изменений на территории Предкавказья // Известия Дагестанского государственного педагогического университета. Естественные и точные науки. 2013. № 2 (23). С. 109-115

6. Бадахова Г.Х., Барекова М.В., Каплан Г.Л. Особенности изменчивости регионального климата сухостепных ландшафтов Ставропольского края // Известия вузов Северного Кавказа. Естественные науки. 2014. № 2. С. 81-85.

7. Бадахова ГХ., Гораль Г.Г., Каплан Л.Г., Федченко Л.М. Роль термического и динамического факторов в разрешении энергии неустойчивости атмосферы // Тр. ВГИ. 1990. Вып.81. С. 84-91.

8. Бадахова Г.Х., Кнутас А.В. Ставропольский край: современные климатические условия. Ставрополь: Краевые сети связи, 2007.

9. Кононова Н.К. Изменения циркуляции атмосферы Северного полушария в XX-XXI столетиях и их последствия для климата // Фундаментальная и прикладная климатология. 2015. Т. 1. № 1. С. $133-162$.

10. Раков В.А., Дульзон А.А. О широтных особенностях грозовой деятельности // Метеорология и гидрология. 1984. № 1. С. 5257.

11. Справочник по климату СССР. Вып. 13. Ч. 5. Облачность и атмосферные явления. Л.: Гидрометеоиздат, 1968

12. Федченко Л.М. Влияние рельефа Северного Кавказа на трансформацию метеорологических элементов и локализацию конвективных процессов // Метеорология и гидрология. 1987. № 6 C. $55-64$.

\section{References}

1. Adzhiev A.H. Klimatologicheskie i statisticheskie harakteristiki groz na Kavkaze // Tr. VGI. 1999. Vyp. 90. S. 64-70.

2. Adzhiev A.H., Adzhieva A.A., Tumgoeva H.A. Vliyanie orografii na harakteristiki grozovoj aktivnosti deyatel'nosti // Izvestiya vuzov. SeveroKavkazskij region. Estestvennye nauki. 2008. № 3. S. 109-112.

3. Adzhiev A.H., Badahova G.H. Dinamika grozovoj aktivnosti $\vee$ regione Kavkazskih Mineral'nyh Vod $v$ XX veke // Fizika oblakov aktivnie vozdejstviya na gidrometeorologicheskie process: Doklady Vserossijskoj konferencii. Moskva, 2008. S. 206-213. 
4. Badahova G.H., Akopov G.A. Vekovoj monitoring grozovoj aktivnosti $\vee$ predgornoj zone Central'nogo Predkavkaz'ya // Teoreticheskie i prakticheskie aspekty nauchnoj mysli $v$ sovremennom mire: Sb. statej mezhdunarodnoj nauchno-prakticheskoj konferencii v 4 chastyah. Orenburg. 2017. S. 25-29.

5. Badahova G.H., Bajramkulova B.O., Gadzhimuradova Z.M., Dzhandubaeva T.Z. Monitoring sovremennyh klimaticheskih izmenenij na territorii Predkavkaz'ya//Izvestiya Dagestanskogo gosudarstvennogo pedagogicheskogo universiteta. Estestvennye i tochnye nauki. 2013. № 2 (23). S. 109-115.

6. Badahova G.H., Barekova M.V., Kaplan G.L. Osobennosti izmenchivosti regional'nogo klimata suhostepnyh landshaftov Stavropol'skogo kraya// Izvestiya vuzov Severnogo Kavkaza. Estestvennye nauki. № 2, 2014. S. 81-85.

7. Badahova G.H., Goral' G.G., Kaplan L.G., Fedchenko L.M. Rol' termicheskogo i dinamicheskogo faktorov $\vee$ razreshenii energii neustojchivosti atmosfery// Tr. VGI. 1990. Vyp. 81. S. 84-91.

8. Badahova G.H., Knutas A.V. Stavropol'skiy kray: sovremennye klimaticheskie usloviya. Stavropol': GUP SK «Kraevye seti svyazi», 2007.

9. Kononova N.K. Izmeneniya cirkulyacii atmosfery Severnogo polushariya $\vee X X-X X \mid$ stoletiyah I ih posledstviya dlya klimata // Fundamental'naya i prikladnaya climatologiya. 2015. T. 1. № 1. S. 133-162.

10. Rakov V.A., Dul'zon A.A. O shirotnyh osobennostyah grozovoj deyatel'nosti // Meteorologiya i gidrologiya. 1984. № 1. S. 52-57.

11. Spravochnik po klimatu SSSR. Vyp. 13. Ch. 5. Oblachnost' i atmosfernye yavleniya. L.: Gidrometeoizdat, 1968.

12. Fedchenko L.M. Vliyanie rel'efa Severnogo Kavkaza na transformatsiyu meteorologicheskih elementov i lokalizatsiyu konvektivnyh protsessov // Meteorologiya i gidrologiya. 1987. № 6. S. 55-64.

\section{O6 авторах}

Бадахова Галина Хамзатовна, ведущий метеоролог Ставропольского центра по гидрометеорологии и мониторингу окружающей среды, ст. преподаватель кафедры общей и теоретической физики ИМЕН СКФУ. Телефон: 8-918-787-56-25.

E-mail: badahovag@mail.ru.

Лашманов Юрий Константинович, зам. начальника Ставропольского центра по гидрометеорологии и мониторингу окружающей среды. Телефон: 8-962-40-56-13 E-mail: skylab2003@mail.ru.

Шимгельский Владимир Андреевич, аспирант кафедры общей и теоретической физики Северо-Кавказского федерального университета. Телефон 8(906) 470-57-25, E-mail: shmigelskiy.92777@mail. ru, ResearcherID is: Q-3869-2018 


\section{About the authors}

Badakhova Galina Khamzatovna, leading meteorologist of the Stavropol Center on hydrometeorology and environmental monitoring, art Lecturer, Department of General and Theoretical Physics, NAME SKFU. Phone: 8-918-787-56-25. E-mail: badahovag@mail.ru.

Lashmanov Yury Konstantinovich, deputy. Head of the Stavropol Center on hydrometeorology and environmental monitoring. Phone: 8-962-4056-13 E-mail: skylab2003@mail.ru.

Shimelsky Vladimir Andreevich, post-graduate student of the Department of General and Theoretical Physics of the North Caucasus Federal University, Phone 8 (906) 470-57-25 E-mail: shmigelskiy.92777@ mail. ru, ResearcherIDis: Q-3869-2018 